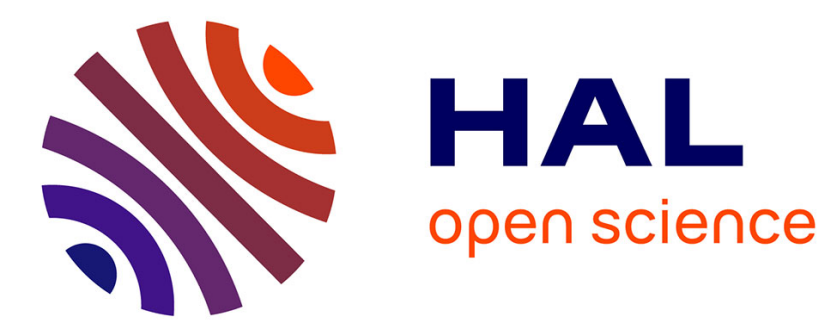

\title{
The rat Mist1 gene: structure and promoter characterization.
}

Claudie Lemercier, Amy Brown, M. Mamani, J. Ripoche, J. Reiffers

\section{To cite this version:}

Claudie Lemercier, Amy Brown, M. Mamani, J. Ripoche, J. Reiffers. The rat Mist1 gene: structure and promoter characterization.. Gene, 2000, 242 (1-2), pp.209-18. hal-00379874

\section{HAL Id: hal-00379874 \\ https://hal.science/hal-00379874}

Submitted on 29 Apr 2009

HAL is a multi-disciplinary open access archive for the deposit and dissemination of scientific research documents, whether they are published or not. The documents may come from teaching and research institutions in France or abroad, or from public or private research centers.
L'archive ouverte pluridisciplinaire HAL, est destinée au dépôt et à la diffusion de documents scientifiques de niveau recherche, publiés ou non, émanant des établissements d'enseignement et de recherche français ou étrangers, des laboratoires publics ou privés. 


\title{
The rat Mist1 gene: structure and promoter characterization
}

\author{
C. Lemercier ${ }^{\mathrm{a}, 1}$, A. Brown ${ }^{\mathrm{b}}$, M. Mamani ${ }^{\mathrm{a}}$, J. Ripoche ${ }^{\mathrm{a}}$ and J. Reiffers ${ }^{\mathrm{a}}$ \\ ${ }^{a}$ Laboratoire de Greffe de Moelle, UMR5540, Université de Bordeaux 2, 33076 Bordeaux \\ Cedex, France \\ ${ }^{\mathrm{b}}$ Department of Biological Sciences, Purdue University, West Lafayette, IN, 47907 USA \\ ${ }^{1}$ Corresonding author at present address: Institut Albert Bonniot, INSERM U309, Equipe \\ Chromatine et Expression des Gènes, Domaine de la Merci, 38706 La Tronche, France.Tel.: \\ +33-4-76-54-95-97; fax: +33-4-76-54-95-95; email: claudie.lemercier@ujf-grenoble.fr
}

Received 30 June 1999; revised 15 November 1999; accepted 18 November 1999

Received by A. Sippel

Available online 2 February 2000.

\begin{abstract}
Transcription factors of the basic Helix-Loop-Helix (bHLH) protein family play key roles in several developmental processes. Mist1 belongs to this group of proteins and shares several properties with the other family members. For example, Mist 1 is capable of dimerization with the ubiquitously expressed E2A bHLH proteins and exhibits a strong DNA-binding activity to the core E-box sequence. Using in-situ hybridization and Northern blot hybridization, Mist 1 mRNA has been detected in a variety of embryonic and adult rodent tissues. To understand the molecular mechanisms involved in the expression of the gene, we have cloned the rat Mistl gene and analyzed $2.5 \mathrm{~kb}$ of its $5^{\prime}$ flanking region. The Mistl gene spans over 5 kilobases and is composed of two exons separated by a unique intron. The entire coding region is localized in the second exon. Sequence analysis of the promoter region indicated an absence of TATA-box or CAAT-box sequence, but several consensus Sp1-binding sites were present near the transcription start site. Deletion analysis of the promoter region identified a $272 \mathrm{bp}$ proximal fragment to be sufficient to drive expression of a reporter gene in NIH3T3 fibroblasts. Subsequent deletion of potential $\mathrm{Sp} 1$ sites results in a marked decrease in promoter activity. Electrophoretic mobility shift assays revealed that Sp1 binds to two different regions in the proximal promoter, a typical Sp1 site located at $(-38 ;-33)$ and a G/Crich region between $(-67 ;-62)$. These data suggest that the basal expression of this TATAless gene might be driven by general transcription factors, such as $\mathrm{Sp} 1$.
\end{abstract}

Author Keywords: bHLH factor; Promoter sequence; Regulatory elements; Sp1

\section{Introduction}

The transcription machinery in eukaryotic cells is tightly regulated by a number of key transcription factors that control tissue-specific gene expression patterns. Among the different transcription factor families that have been identified, the basic helix-loop-helix (bHLH) family stands out as an essential regulator of many different developmental pathways. Members of this family exhibit a common structural motif known as the helix-loop-helix (HLH) region, which consists of two $\alpha$-amphipathic helices separated by a variable loop (Ma and Murre). Immediately adjacent to the HLH is a basic region that is required for DNA- 
binding ( Blackwell and Weintraub, 1990). The HLH domain is involved in protein dimerization with other bHLH factors, mediating the formation of bHLH dimers that bind to the DNA consensus E-box site (-CANNTG-) found in many structural genes ( Murre et al., 1989b). A consequence of the binding of bHLH proteins to DNA targets is the transcriptional activation or repression of specific genes. Based on their expression pattern, bHLH factors are classified in two major categories. The 'tissue-specific' bHLH proteins are only found in a particular tissue or cell-type, i.e. the MyoD family in skeletal muscle (reviewed in Ludolph and Molkentin), the neurogenic Mash1, NeuroD or HES family members in neuronal cells (see Kageyama et al., 1997 for a review) or the Tal-1 protein in hematopoietic cells ( Shivadasani and Orkin, 1996). Other factors, such as the E2A gene products, E12 and E47, are called 'ubiquitous' since they are expressed in virtually every cell ( Murre et al., 1989a). In general, tissue-specific bHLH factors form heterodimers with a partner of the ubiquitous protein family, i.e. MyoD:E12 in skeletal muscle, and this high-affinity, stable complex binds to an E-box sequence to regulate gene transcription (Blackwell; Lassar and Murre).

We recently identified a novel bHLH factor, Mist1 Mak et al., 1996), that is capable of forming heterodimers with E12 and E47. In addition, Mist1 forms homodimers that also bind to E-box sequences ( Lemercier et al., 1997). In skeletal muscle, the Mist1 protein accumulates in undifferentiated myoblasts, but rapidly decreases as the cells differentiate into myotubes. Our studies have also shown that Mist1 associates with the myogenic bHLH factor MyoD and represses MyoD from activating gene transcription in myogenic cells ( Lemercier et al., 1998). Thus, Mist1 functions as a bHLH repressor in skeletal muscle. As detected by insitu hybridization in the mouse embryo, Mist1 mRNA also is found in the primitive gut and organs of the gastro-intestinal tract (pancreas, intestine, submandibulary gland), as well as in the olfactory epithelium and lung ( Lemercier et al., 1997). In adult rat tissues, Northern blot analysis indicates that Mist 1 mRNA is present in stomach, liver, spleen, skeletal muscle, testis and olfactory epithelium. However, the role(s) of Mist 1 in these tissues remains to be elucidated.

The molecular mechanisms that regulate transcription of the Mist1 gene are unknown. Previous studies of eukaryotic class II promoters have shown that they can be dissected into a basal core promoter (frequently containing a TATA box) and distal enhancer elements. The TATA box is typically located at $25-30 \mathrm{bp}$ upstream from the transcription start site and is bound by TFIID, an essential transcription factor composed of the TATA binding protein (TBP) and TBP-associated factors (TAFs) (reviewed in Burley and Hahn). A growing number of genes have been discovered that do not contain a TATA-box element, and it has been found that the transcription initiation complex, including TBP and its associated factors, can still bind to this upstream region if appropriate tethering elements are present. In order to investigate the molecular mechanisms controlling the expression of the Mistl gene, we isolated genomic clones and analyzed the $5^{\prime}$ flanking region for promoter activity.

\section{Materials and methods}

\subsection{Cell culture}

NIH3T3 cells (mouse embryo fibroblasts) were cultured in Dulbecco's modified Eagle's medium (DMEM) supplemented with $10 \%$ fetal calf serum (FCS), $2 \mathrm{mM}$ L-glutamine, penicillin $(100 \mathrm{IU} / \mathrm{ml})$ and streptomycin $(100 \mu \mathrm{g} / \mathrm{ml})$. C2C7 mouse myogenic cells were maintained in DMEM:Ham F12 (1:1) supplemented as above. Terminal differentiation into myotubes was induced by replacing the culture medium with a high-glucose DMEM containing $2 \%$ horse serum for 2 days. 


\subsection{Northern blots}

Total RNA was extracted from mouse cell lines using RNAble solution (Eurobio). Fifteen micrograms of total RNA were separated through a denaturing formaldehyde gel, transferred to nitrocellulose (BioBond-NC, Whatman) and hybridized with a ${ }^{32} \mathrm{P}-1$ labeled mouse Mist 1 cDNA probe (GenBank Accession No. AF049660). After high-stringency washes, the blots were subjected to autoradiography. To normalize for RNA content, each blot was also probed with a mouse $G A P D H$ cDNA.

\subsection{Cloning of the rat Mist1 gene}

Two rat Mistl genomic clones were obtained by screening an EMBL3 genomic library (Clontech) with a ${ }^{32} \mathrm{P}$-labeled Mist 1 cDNA probe. Phage clone I (13 kb insert) was isolated using a rat Mist l cDNA probe encoding amino acids 88-197. Subsequently, phage clone II (14 kb insert) was identified using a $5^{\prime}$ probe (containing the last $127 \mathrm{bp}$ of intron 1 and part of the coding region) derived from clone I. After restriction digest analysis, a $7 \mathrm{~kb}$ SacI fragment derived from clone I and a $3.3 \mathrm{~kb}$ SalI fragment obtained from clone II were subcloned in pBSKS+ plasmid (Stratagene). Inserts were sequenced on both strands, and a DNA sequence analysis was performed using Mac Vector and Blast software programs. Transcription factor consensus binding sites were analyzed with the TFD database. The gene sequence has been deposited in GenBank (AF049874).

\subsection{5 ' extension analysis}

The transcription start site in the rat Mist 1 gene was determined by $5^{\prime}$ extension analysis according to the manufacturer's instructions (Primer Extension System kit, Promega). The primer designed for this experiment (5'-ACTGGGGATCCGAGGCCGTA-3') is positioned $50 \mathrm{bp}$ upstream of the initiation ATG. The extension reaction was performed from $0.5 \mu \mathrm{g}$ of rat spleen poly $(\mathrm{A})^{+}$RNA (Clontech). One tenth of the reaction was loaded on to a $7 \%$ sequencing gel, along with ${ }^{32} \mathrm{P}-\Phi X 174$ HinfI markers. The gel was exposed to X-ray film with an intensifying screen at $-80^{\circ} \mathrm{C}$ for $15 \mathrm{~h}$.

\subsection{Luciferase reporter constructs}

A $2588 \mathrm{bp}$ Mistl promoter fragment was amplified by PCR from clone II using T3 oligonucleotide and Mist 1 specific primer A (5'-ggggtaccGAGGCCGTACGCGCAG-3'). The PCR product was digested with $K p n I$ and ligated upstream of the luciferase reporter gene in the pGL2-basic plasmid (Promega). All PCR amplifications were performed using a proofreading polymerase mix of Taq/Pwo (Expand High Fidelity PCR system, Boehringer Mannheim). Deletions in the WT fragment $(-2492$ to +66$)$ were generated as above by PCR using the following primers $\left(5^{\prime}\right.$ to $\left.3^{\prime}\right)$ : Mistl ( -2492 to -198$)$ : cgggtaccTTGGGGTCACGAC and T3, Mist 1 ( -2492 to -464$)$ : cgggtaccTGACAATTGGGAAAAC and T3. For the deletions of the $5^{\prime}$ end: primer $A$ (see above) and the following primers $\left(5^{\prime}\right.$ to $\left.3^{\prime}\right)$ : cgggtaccAATTGTCAGAC ( -475 to +66$)$, cgggtaccCCAAGGCCAGGT (-206 to +66), cgggtaccAGGTGCCGCCCTGG ( -55 to +66$)$, cgggtaccTGCCGCCCTGGCCCCGC $(-51$ to $+66)$, cgggtaccAGCGAGCTCATTTAC $(-34$ to +66$)$. The PCR products were cloned into pGL2basic at the KpnI site. Mutations of the Sp1 site b in the $(-206,+66)$ construct were achieved by PCR using the overlapping mutated oligonucleotides $\left(5^{\prime}\right.$ to $\left.3^{\prime}\right)$ : GCCCTGGCCgatCCCAGCTC (+ strand) and CTCGCTGGGatcGGCCAGGCGGCAC (strand). Mutations were confirmed by DNA sequencing.

\subsection{Cell transfections}

Transfections in NIH3T3 cells were performed with $2 \mu \mathrm{g}$ of a calcium phosphate DNA precipitate containing various Mistl promoter constructs. After 2 days, cell extracts were 
prepared and assayed for luciferase activity and protein content as described previously (Lemercier et al., 1997). Luciferase values were normalized to protein levels and are expressed as fold over control (pGL2 basic vector). Each value represents the average $( \pm$ SEM) of at least four experiments. Over-expression of Mist 1 in NIH3T3 cells was obtained by transfecting the cells with $10 \mu \mathrm{g}$ of pcDNA-Mist1 plasmid (Lemercier et al., 1997).

\subsection{Western blot}

Western blot analyses were performed as described in detail previously (Lemercier et al., 1998)

\subsection{Electrophoretic mobility shift assays (EMSA)}

Nuclear extracts from NIH3T3 cells were prepared as described previously (Lassar et al., 1991). Protein concentration was determined using the BioRad protein assay reagent. EMSA was performed as described previously ( Lemercier et al., 1998). Oligonucleotides were endlabeled with $\gamma^{32} \mathrm{P}$-ATP and T4 polynucleotide kinase. After removal of unincorporated nucleotides, the sense and antisense strands were annealed and used as a probe. The following oligonucleotides were tested (sequence of the + strand, $5^{\prime}$ to $3^{\prime}$ ):

WT -54; -29: AGGTGCCGCCCTGGCCCCGCCCAGCG

mut a: AGGTGgatCCCTGGCCCCGCCCAGCG

mut b: AGGTGCCGCCCTGGCCgatCCCAGCG

mut a/b: AGGTGgatCCCTGGCCgatCCCAGCG

$-63 ;-38$ : CGTGGCCGCAGGTGCCGCCCTGGCC

-72; -48: AGCGAGGGGCGTGGCCGCAGGTGCC

mut dist: AGCGAGtaaCGTGGCCGCAGGTGCC mut prox: AGCGAGGGGCGTGtaaGCAGGTGCC.

For competition experiments a 100-fold molar excess of unlabeled probe was included in the reaction. In supershift experiments, $300 \mathrm{ng}$ of polyclonal antibody directed against Sp1, E47 and AP2 $\alpha$ (Santa Cruz, PEP-2, N-649 and C-18 antiserum, respectively) were preincubated for $15 \mathrm{~min}$ at room temperature with the NIH3T3 nuclear extracts prior to the addition of the labeled probe. DNA:protein complexes were resolved on a $4 \% 0.5 \times$ TBE acrylamide gel and visualized by autoradiography.

\section{Results and discussion}

\subsection{Isolation and structure of the rat Mist 1 gene}

The cloning of the entire Mist 1 rat cDNA has been previously reported (Lemercier et al., 1997). The next step led us to the isolation and the characterization of the Mist 1 gene. A phage EMBL3 rat genomic library was screened using a rat Mist1 cDNA probe encoding for amino acids 88-197. A first positive phage (clone I, $13 \mathrm{~kb}$ insert) was isolated (Fig. 1). Subsequently, another screen was performed with the most $5^{\prime}$ sequence derived from clone I. A second overlapping phage (clone II) was obtained that contained additional $5^{\prime}$ sequence (Fig. 1). Cloning and sequencing of the two clones showed the Mistl gene to be composed of two exons separated by a single 656 bp intron (Fig. 2). The intron/exon borders follow the classical GT/AG splice rules. The first exon is $73 \mathrm{bp}$ long and consists entirely of $5^{\prime}$ untranslated sequence. The second exon spans over $3.5 \mathrm{~kb}$ and contains the entire coding region plus the $3^{\prime}$ untranslated sequence. Taken together, the Mistl gene is positioned within less than $5 \mathrm{~kb}$ of genomic DNA. 


\subsection{Promoter sequence of the Mist1 gene}

The sequence of approximately $2.5 \mathrm{~kb}$ of the $5^{\prime}$ region flanking the Mistl gene was established from clone II (Fig. 2A). The transcription start site was mapped by $5^{\prime}$ primer extension analysis using an oligonucleotide positioned 50 bases upstream of the initiation ATG and poly(A) ${ }^{+}$RNA obtained from rat spleen. A major product of 75 bases was obtained (Fig. 2B, lane E), which indicates that the $5^{\prime}$ untranslated sequence is $124 \mathrm{bp}$ long. These data are in full agreement with our previous report on the isolation of the rat Mistl cDNA by $5^{\prime}$ RACE strategies (Lemercier et al., 1997). Therefore, the first nucleotide of the cDNA is referred to as +1 , and the first base within the promoter as -1 . Sequence analysis and database homology searches revealed that the Mistl gene does not exhibit a typical TATA-box motif near the transcription start site but instead has a related TcATTTAcAT sequence located at -25 (Fig. 2A). Two consensus Sp1 binding sites ( Briggs et al., 1986) are present on the minus strand at positions $(-38 ;-33)$ and $(-49 ;-44)$ as well as an AP-2 binding site (GCCGCGGGC, Williams and Tjian, 1991) at -130 and a PU.1 site (GAGGGAAA, Klemsz et al., 1990) at -105 . A striking feature in the Mistl promoter region is the presence of 21 putative E-box sites (CANNTG), named E1 to E21, raising the possibility that Mistl gene expression is regulated through binding of specific bHLH factors.

\subsection{The Mist1 promoter is functional in NIH3T3 and $\mathrm{C} 2 \mathrm{C} 7$ cells}

In order to confirm the presence of functional promoter regulatory elements, the putative promoter region (about $2.5 \mathrm{~kb}$ ) plus $66 \mathrm{bp}$ of exon 1 was ligated $5^{\prime}$ to a luciferase reporter gene (Mist WT-Luc), and the activity of the promoter was tested by transient DNA transfections in NIH3T3 fibroblasts and in $\mathrm{C} 2 \mathrm{C} 7$ myogenic cells. Because Mist1 expression was not detected in a number of tissues (i.e. brain and heart; Lemercier et al., 1997), we first verified that endogenous Mist1 was expressed in these two cell lines by testing for the presence of Mist 1 mRNA and protein. Mist 1 mRNA $(3.6 \mathrm{~kb})$ was detected in both cell types by Northern blot, indicating that the endogenous Mistl gene is active (Fig. 3A). Using a polyclonal rabbit serum raised against a GST-Mist1 fusion protein, we also confirmed that Mist1 protein was present in extracts from C2C7 and NIH3T3 cells (Fig. 3B). As reported before ( Lemercier et al., 1998), Mist1 is expressed in C2C7 myoblasts (MB lane) but not in terminally differentiated myotubes (MT lane). Mist1 protein was also detected in NIH3T3 control cells ( $\mathrm{C}$ lane, endogenous protein) and in much larger amounts in cells tranfected with a Mist1 expression plasmid (Tx lane). No signal was obtained with the pre-immune serum or an irrelevant normal rabbit serum (data not shown). Thus, these data indicated that NIH3T3 and $\mathrm{C} 2 \mathrm{C} 7$ cells can be used as a model system to study Mist 1 promoter activity.

When the Mist WT-Luc plasmid was tested in NIH3T3 cells (Fig. 3C, white bar), 90fold higher luciferase levels were obtained compared to the promoter-less plasmid (black bar). This result indicates that the $2.5 \mathrm{~kb}$ Mist1 5 '-flanking region contains a functional promoter that allows the transcription of a reporter gene. In $\mathrm{C} 2 \mathrm{C} 7$ myogenic cells, we analyzed the expression of Mist WT-luc in myoblasts kept in a proliferative state (high serum growth medium) or in cells induced to terminally differentiate into myotubes upon serum deprivation. In this case, a muscle-specific gene such as the troponin I gene (TnI-luc, Johnson et al., 1996) becomes highly expressed in differentiated myotubes ( $>250$-fold over control, gray bar), whereas a low level of TnI-luc activity is detected in myoblasts ( Fig. 3C). When tested under similar conditions, a high luciferase expression was obtained with the Mist WT-luc reporter in proliferating myoblasts (215-fold above the control), whereas the activity of the promoter decreases as the cells are induced to differentiate into myotubes (77-fold above the control). Thus, the Mist 1 gene behaves in an opposite fashion to the TnI gene in myogenic cells. However, we do not know at present whether the lower activity of Mist 1 promoter in 
differentiated cells is due to cell-cycle arrest upon serum deprivation or to a specific inhibition mechanism.

\subsection{Deletion analysis of the Mist1 promoter}

To delineate the sequences responsible for the basal promoter activity, several deletion constructs that lacked either the proximal $(\Delta 1$ and $\Delta 2)$ or distal promoter sequences $(\Delta 3$ to $\Delta 7)$ were generated by PCR. The $\Delta 1$ and $\Delta 2$ constructs, which lack 197 and 463 nucleotides of proximal sequence, respectively, showed a greatly reduced promoter activity when compared to the Mist1 WT-Luc construct (Fig. 4). In contrast, $\Delta 3$ and $\Delta 4$ constructs, containing only 475 and $206 \mathrm{bp}$ of proximal sequence, exhibited almost full promoter activity in this system. These results indicate that a $272 \mathrm{bp}$ fragment $(-206$ to +66$)$ contains the regulatory element sufficient to allow the transcription of the luciferase reporter gene. Further deletions of the two E-boxes E3 and E2 and a putative AP-2 site $(\Delta 6)$ or the E1 E-box sequence $(\Delta 5)$ lead to a marked decrease in luciferase activity. Constructs bearing an additional deletion of the two consensus Sp1 binding sites $(\Delta 7)$ did not exhibit promoter activity, suggesting that $\mathrm{Sp} 1$ binding at these positions is critical for Mistl gene expression. The lack of activity of this latter construct also indicates that the TATA-related sequence at position -25 is not sufficient to confer transcriptional activity on this gene.

\subsection{Sp1 has two binding sites in the Mist1 proximal promoter}

To further examine the hypothesis that $\mathrm{Sp} 1$ binds to the Mist 1 promoter, EMSA was performed using the two consensus Sp1 binding sites as probes $(-54$ to -29$)$ and NIH3T3 nuclear extracts. The ${ }^{32} \mathrm{P}$-labeled Sp1 probe was incubated with NIH3T3 nuclear extracts and the DNA:protein complexes were resolved on a non-denaturing gel and visualized by autoradiography. As shown in Fig. 5A, three probe-bound complexes were detected. The formation of these complexes was efficiently inhibited by a 100 -fold molar excess of the cold probe $(100 \times$ WT), indicating a specific protein:DNA interaction. Since the oligonucleotide sequence contains two potential Sp1 binding sites, we next looked for the presence of Sp1 protein using an antibody specific for Sp1. When NIH3T3 extracts were incubated with anti$\mathrm{Sp} 1$, complex 1 was greatly reduced, while a supershifted complex $\left({ }^{* *}\right)$ appeared. This new complex was not detected when antibodies against unrelated factors (AP2 and E47 proteins) were tested. This result indicates that endogenous Sp1 present in extracts from NIH3T3 cells can bind to the Mist 1 promoter. Further investigations will be required to discover the identity of the proteins contained within complexes 2 and 3 . To further characterize the Sp1 binding complexes, EMSA was conducted with mutant oligonucleotide probes. Mutations were introduced in the -54 to -29 DNA probe (see Section 2 and Fig. 6A) to disrupt the putative $\mathrm{Sp} 1$ site a (mut $\mathrm{a}$ ), site $\mathrm{b}$ (mut b) or both sites simultaneously (mut $\mathrm{a} / \mathrm{b}$ ). A 100 -fold molar excess of cold mut a inhibits Sp1 binding as efficiently as the wild-type (WT) probe (Fig. 5B). Surprisingly, complexes 2 and 3 are also competed by mut $a$. In contrast, the mut $b$ oligonucleotide, and the double mutant $\mathrm{a} / \mathrm{b}$, are unable to compete for $\mathrm{Sp} 1$ binding. These data were confirmed by labelling mut a and mut $b$ probes and incubating them with NIH3T3 nuclear extracts. In these conditions, mut a probe, but not mut $\mathrm{b}$, was capable of binding $\mathrm{Sp} 1$ (data not shown). Together, these experiments suggest that site $b$ avidly binds Sp1, whereas site $\mathrm{a}$ is not functional in this assay.

To confirm the importance of the $\mathrm{Sp} 1$ site $\mathrm{b}$ in vivo, a mutation was introduced on site $\mathrm{b}$ in the $\Delta 4$ Mist 1 promoter fragment $(-206 ;+66)$ by PCR mutagenesis (CCGCCC altered to CgatCC). The activity of the original and the mutated promoter region was tested in NIH3T3 cells (Fig. 5C). As expected, disruption of the $\mathrm{Sp} 1$ site $\mathrm{b}$ led to a marked reduction in promoter activity (65\% decrease), indicating that $\mathrm{Sp} 1$ binding at this position contributes to the activation of the Mist 1 promoter. These data also suggest that additional DNA sequences 
in the $\Delta 4$ construct are involved in the activity of the promoter since one-third of the luciferase activity is still detected with the mutated Sp1b construct.

G/C-rich elements are located immediately upstream the E-box E1 (Fig. 6A). Although they do not represent classical Sp1 sites, we performed EMSA with additional oligonucleotides covering the -72 to -48 or the -63 to -38 regions. When increasing amounts of NIH3T3 nuclear extract $(0-10 \mu \mathrm{g})$ were incubated with the -72 to -48 probe, a strong Sp1 binding complex could be detected (Fig. 6B, left panel). The signals obtained are comparable to those obtained with the -54 to $-29 \mathrm{Sp} 1$ probe ( Fig. $6 \mathrm{~B}$, right panel). In contrast, only a weak binding activity is detected with the -63 to -38 probe, even in the presence of large amounts of nuclear extract ( Fig. 6B, middle panel). Since this latter oligonucleotide contains the $\mathrm{Sp} 1$ site a (not functional) and the most proximal G/C element (weak binding), it is likely that the distal $\mathrm{G} / \mathrm{C}$ site in the -72 to -48 probe represents another strong $\mathrm{Sp} 1$ binding site.

This issue was addressed in competition experiments with an excess of cold mutant oligonucleotides for the $\mathrm{G} / \mathrm{C}$ distal or proximal regions (Fig. 6A). As expected, competition for $\mathrm{Sp} 1$ binding was obtained with an 100 -fold excess of the non-radioactive $-72 ;-48$ probe, or with an oligonucleotide bearing a mutated proximal $\mathrm{G} / \mathrm{C}$ site ( Fig. $6 \mathrm{C}$, mut prox), indicating that this proximal G/C element is not necessary for competing Sp1. In contrast, an intact distal $\mathrm{G} / \mathrm{C}$ element is required, since a mutant distal G/C oligonucleotide (mut dist) has no competitive effect on $\mathrm{Sp} 1$ binding to the probe. Finally, we also tested whether cold $\mathrm{Sp} 1$ site $b$ could interfere with Sp1 binding to the distal G/C element. Indeed, the incubation of nuclear extracts with an excess of cold $-54 ;-29$ DNA inhibited $\mathrm{Sp} 1$ binding to the labeled probe, whereas mut b was inefficient ( Fig. 6C). This result suggests that the G/C distal element and the $\mathrm{Sp} 1$ site $\mathrm{b}$ might be functionally equivalent in the Mistl promoter.

\section{Conclusions}

The Mist 1 transcription factor belongs to the basic Helix-Loop-Helix protein family, which is known to play important roles during embryonic development and in cell fate determination. In this work, we have cloned the rat Mistl gene, determined its intron/exon structure and analyzed its $5^{\prime}$ flanking region for promoter activity. Our analysis showed that the Mist 1 gene consists of two exons separated by a single intron and that the whole gene is contained within less than $5 \mathrm{~kb}$ of genomic DNA. Special features in the gene include the presence of an uninterrupted coding region in exon II and a very large $3^{\prime}$ untranslated region $(2.8 \mathrm{~kb})$.

Sequence analysis of genomic clones containing the promoter region of the rat Mist 1 gene reveals many features that are common to constitutively active eukaryotic promoters, including the absence of classical TATA and CAAT-box sequences and a high GC content. Although no typical initiator element $\left(\mathrm{PyPyCA}^{+1} \mathrm{NT} / \mathrm{APyPy}\right.$, Smale and Baltimore, 1989) was found, a major product was obtained upon mapping of the transcription start site, indicating that the transcription is not initiated at multiple points but rather at a precise site.

Promoter deletion analysis suggests that $\mathrm{Sp} 1$ binding sites are necessary for the transcriptional activation of the Mist 1 gene. Pugh and Pugh showed that Sp1 transcription from a TATA-less promoter required a multisubunit TFIID complex that includes TBP, TBP-associated factor (TAFs), coactivators and Sp1. It is thought that Sp1 might be anchoring TBP to the TATAless promoter via tethering factors such as TAF110 ( Hoey et al., 1993). Our study indicates that $\mathrm{Sp} 1$ binds to two different regions within the proximal promoter, a typical Sp1 site located at $(-38 ;-33)$ and a G/C-rich region between $(-67 ;-62)$. In the context of the TATAless, Inr-less Mist 1 promoter, it is possible that $\mathrm{Sp} 1$ serves as a bridging molecule to allow the assembly of the preinitiation complex. Moreover, two additional factors, that also bind to or near the Sp1 sites, might also contribute to the basal expression of this gene. Our future 
studies will aim to identify these two proteins as well as other transcription factors that might regulate the Mist 1 gene during embryonic development and cell differentiation.

\section{Acknowledgements}

This work was supported by La Ligue Nationale Contre Le Cancer et L'Université Victor Ségalen Bordeaux 2. We thank Dr J. Gaffé, Dr S. Khochbin, Dr S.E. Johnson, Professor S. Nanchev and Dr M. Callanan for helpful comments on the manuscript and Dr S.F. Konieczny for reagents and communication of results.

Abbreviations: bHLH, basic Helix-Loop-Helix; EMSA, electrophoretic mobility shift assay

GenBank Accession No. AF049874 (rat Mistl gene) and AF049660 (mouse Mistl cDNA).

\section{References}

Blackwell, T.K. and Weintraub, H., 1990. Differences and similarities in DNA-binding preferences of MyoD and E2A protein complexes revealed by binding site selection. Science 250, pp. 1104-1110.

Briggs, M.R., Kadonaga, J.T., Bell, S.P. and Tjian, R., 1986. Purification and biochemical characterization of the promoter-specific transcription factor, Sp1. Science 234, pp. 47-52.

Burley, S.K. and Roeder, R.G., 1996. Biochemistry and structural biology of transcription factor IID (TFIID). Anmu. Rev. Biochem. 65, pp. 769-799.

Hahn, S., 1998. The role of TAFs in RNA polymerase II transcription. Cell 95, pp. 579-582. Hoey, T., Weinzierl, R.O.J., Gill, G., Chen, J.L., Dynlacht, B.D. and Tjian, R., 1993.

Molecular cloning and functional analysis of Drosophila TAF110 reveal properties expected of coactivators. Cell 72, pp. 247-260.

Johnson, S.E., Wang, X., Hardy, S., Taparowsky, E.J. and Konieczny, S.F., 1996. Casein kinase II increases the transcriptional activities of MRF4 and MyoD independently of their direct phosphorylation. Mol. Cell. Biol. 16, pp. 1604-1613.

Kageyama, R., Ishibashi, M., Takebayashi, K. and Tomita, K., 1997. bHLH transcription factors and mammalian neuronal differentiation. Int. J. Biochem. Cell Biol. 29, pp. 13891399.

Klemsz, M.J., McKercher, S.R., Celada, A., Van Beveren, C. and Maki, R.A., 1990. The macrophage and B cell-specific transcription factor PU.1 is related to the ets oncogene. Cell 61, pp. 113-124.

Lassar, A.B., Davis, R.L., Wright, W.E., Kadesh, T., Murre, C., Voronova, A., Baltimore, D. and Weintraub, H., 1991. Functional activity of myogenic HLH proteins requires heterooligomerisation with E12/E47-like proteins in vivo. Cell 66, pp. 305-315. 
Lemercier, C., To, R.Q., Swanson, B.J., Lyons, G.E. and Konieczny, S.F., 1997. Mist1: A novel basic helix-loop-helix transcription factor exhibits a developmentally regulated expression pattern. Dev. Biol. 182, pp. 101-113.

Lemercier, C., To, R.Q, Carrasco, R.A. and Konieczny, S.F., 1998. The basic helix-loophelix transcription factor Mist1 functions as a transcriptional repressor of MyoD. EMBO J. 17, pp. 1412-1422.

Ludolph, D.C. and Konieczny, S.F., 1995. Transcription factor families: muscling in on the myogenic program. FASEB J. 9, pp. 1595-1604.

Ma, P.C., Rould, M.A., Weintraub, H. and Pabo, C.O., 1994. Crystal structure of the MyoD bHLH domain-DNA complex: Perspectives on DNA recognition and implications for transcriptional activation. Cell 77, pp. 451-459.

Mak, K.L., Longcor, L.C., Johnson, S.E., Lemercier, C., To, R.Q. and Konieczny, S.F., 1996. Examination of mammalian basic helix-loop-helix transcription factors using a yeast onehybrid system. DNA Cell Biol. 15, pp. 1-8.

Molkentin, J.D. and Olson, E.N., 1996. Defining the regulatory networks for muscle development. Curr. Opin. Dev. 6, pp. 445-453.

Murre, C., McCaw, P.S. and Baltimore, D., 1989. A new DNA binding and dimerization motif in immunoglobulin enhancer binding daughterless MyoD, and myc proteins. Cell 56, pp. $777-783$.

Murre, C., Schonleber-McCaw, P., Vaessin, H., Caudy, M., Jan, L.Y., Jan, Y.N., Cabrera, C.V., Buskin, J.N., Hauschka, S.D., Lassar, A.B., Weintraub, H. and Baltimore, D., 1989. Interactions between heterologous helix-loop-helix proteins generate complexes that bind specifically to a common DNA sequence. Cell 58, pp. 537-544.

Pugh, B.F. and Tjian, R., 1990. Mechanism of transcriptional activation by Sp1. Evidence for coactivators. Cell 61, pp. 1187-1197.

Pugh, B.F. and Tjian, R., 1991. Transcription from a TATA-less promoter requires a multisubunit TFIID complex. Genes Dev. 5, pp. 1935-1945.

Shivadasani, R.A. and Orkin, S.H., 1996. The transcriptional control of hematopoiesis. Blood 87, pp. 4025-4039

Smale, S.T. and Baltimore, D., 1989. The initiator as a transcription control element. Cell 57, pp. 103-113.

Williams, T. and Tjian, R., 1991. Analysis of the DNA-binding and activation properties of the human transcription factor AP-2. Genes Dev. 5, pp. 670-682. 


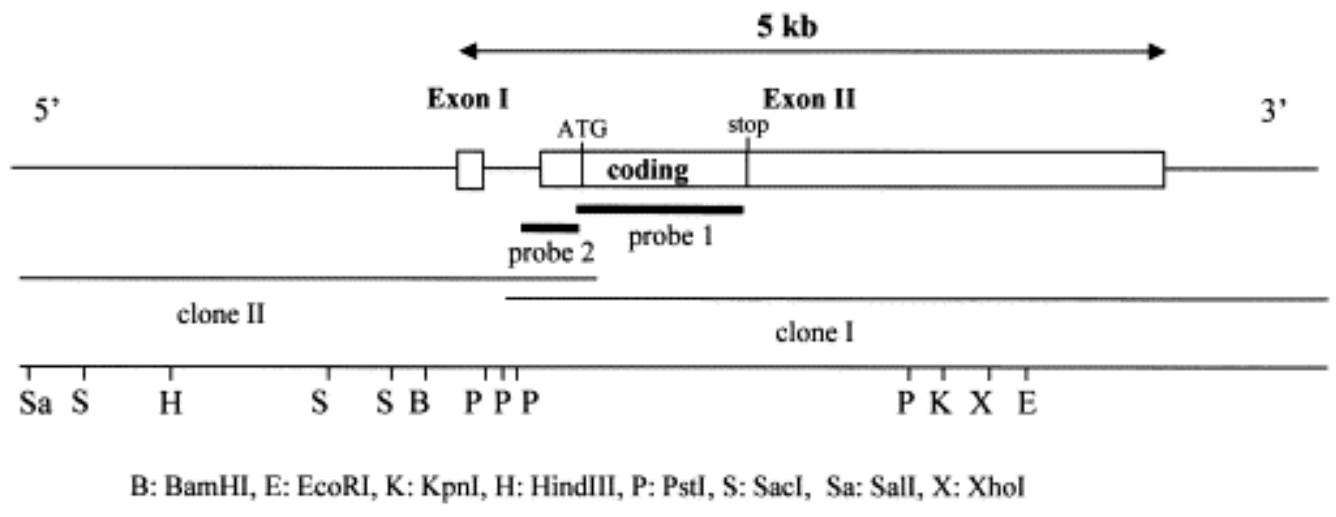

Fig. 1. Intron/exon structure of the rat Mistl gene. The two probes used in the screening procedures are indicated by thick bars. The relative positions of the two isolated genomic clones are given (clone I and clone II). 
-2494 GTCGACAGTATTGCGTCACCCGCTGCTGTCCCGGGCTTGAACAGACGONGTTTGGTTHGCCTGCATAGGCAAAGCTGGGTCTTGGTGACT -2405

-2404 GGACTTGTGCATGTGCCCACTOTTTCGTCCCGNCCACGGCCAGGGATCTGGGCAGGCAGTCACACCCATAGCCCGGCACCTACGAGGTT -2315

-23/4 GTACTTAACACAATCAGATGGGGTCACGGCAATATAACAGTTAATGAACTTGGAGTTTAAATTGTGTACATTTTTAAATTGTAAGATTT -2225

\section{T/A rich}

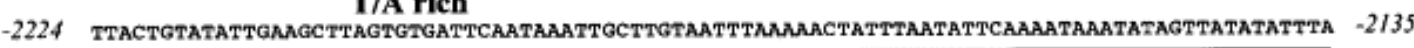

-2134 TAATAATCTCCGTTOCTATGTTTATTCCTTGTTTTTCCATGTGTGGGTTTGGCCCACTGATGTAGATCTCTGAGCTCCCCACAGTCCTA -2045

-2044 AGGGCATGGGATGGTTCTCAGGGGACCATAGAGTCTGCCTGTGTGGCTGTGGGTTCTGTAATCCAAGCCTTTCTACTTACTGAGGAGTC -1955

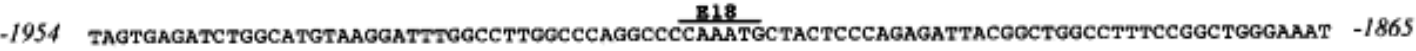

-1864 GGCTTATTTGCTGAGACGaCCCATGTTCAGTTTCTAAAACCCATGATGTTTGARAATGAAAAGGTCAGGTAGAGTGGAGCCTGTGTGCAT -1775

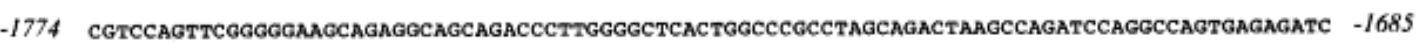

-1684 CTGCCTCAAAACCAACAAAGTGGTOCACCTOAGAACARCTGATGTTGAACACTTTGCTGGTTCACATCCGTTGGCACACAACATGCGCGT -1595

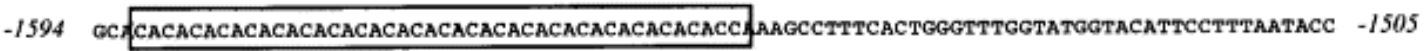

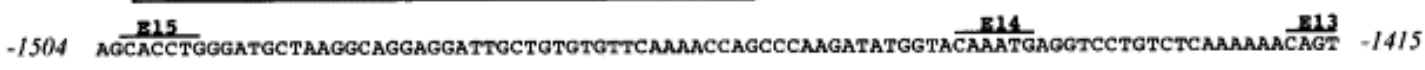

-14/4 TGTATGCAGTATGGGGGCATCTCAGCTCTGACCCCTCTCTCCAGTTCTTTCACTGARGTCCAAGTGACATGAGGGAGGTACAGCTTTCT -1325

-1324 ACCAGAACCACTAACCACATGGCTGTGTCACCAGCCTGAGACCCAAGCCTGCTGAACAGAGAACTCACCCAGAGTTATGCAGAGTCCTGG -I235

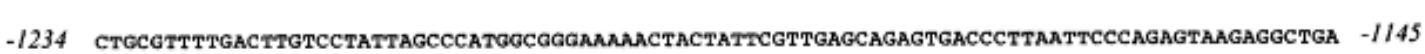

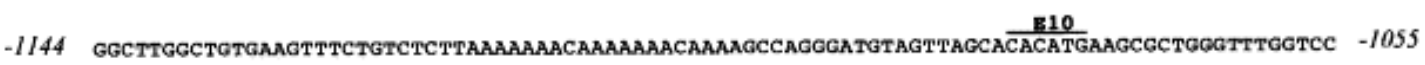

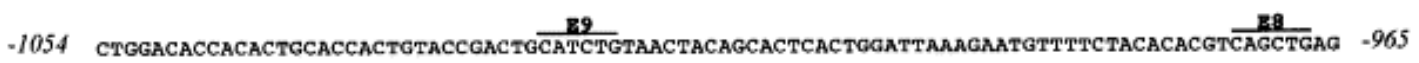

-964 TETGTGCGGTGACCCACTTGCAGTTCTACCCCTTGCGAGCAGAGGAGAGGCTGGAGGATCAGGTOETGCTCAMGGCAGCCTGCGTGTT -875

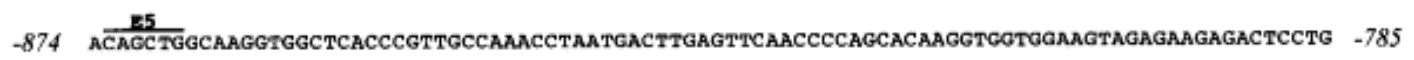

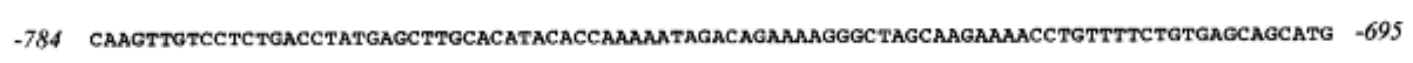

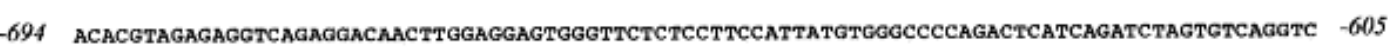

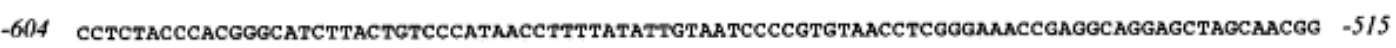

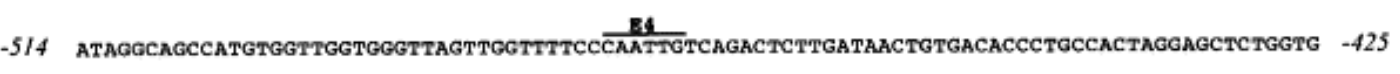

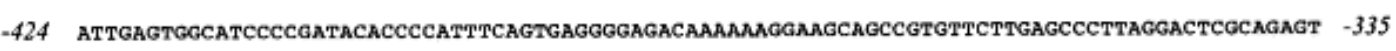

-334 CCGCTGGAAAATCAGCACGCCCTAGGGCAGgGGAaGAGGTCTTGCCAGCTTTGCTCAGCONGGTGGCTGCGGTTCCTGTAAGACTGCGC -245

-244 AGGGTGGCTTATCCTAGACTCTOTTCTGAGTCGTGACCCCAAGGCCAGGTGTCCTGGCCAGGTGCGATCCGGAGTTCCCCTCCCCCAACC -I55

-154 cCGCTCCGGTAATCCCCGGGAGGCCGCGGGCTCTCAGACCCAGAGGGAGGAAAGGGAGGCGGGTCCOCACCGGTCCTCAGAGCGAGGG -65

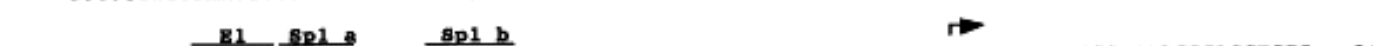

-64 GCGTGGCCOCAGGTGCCGCCCTGGCCCCGCCCAGCGAGCTCATTTACATGCTTCCCGCAGCCCCGCCTGTGGTGGCTAAAGCGACGTGTC +26 CTTGTCCCCCGTGGGCAGCCTCTGCGCGTACGGCCTCGCATCCCCAGgtaaAccaaggggtt tggggaactggatgggactgetgggaag ggacecagaagcgggaccagaggacctgeageggtagggggaaaacagatagatggtggcttccacteagactggctggtgccgtccacg tggtagatctggggget getgcagggccttggccaccgtcagtctgacetgtcagctgtccgtgtgtgcatgcactgeggttetggttct gataatgtctggacttgtgtcatgtceaggagagctgtaatatagtggtctaaggggtgctgcttgtetcgggtgacagtgtcgggtgg

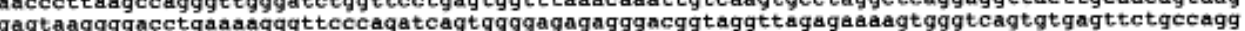
gagtalog caltgagatcgctgagctgcatgeccactggccacgctgaatgactgcagaggggetgtgttctgatttcagTCGGAACCCCTCTCCC AGCCACCACCTCCTGGGAAAAACAGCCTAGAGCTATG 


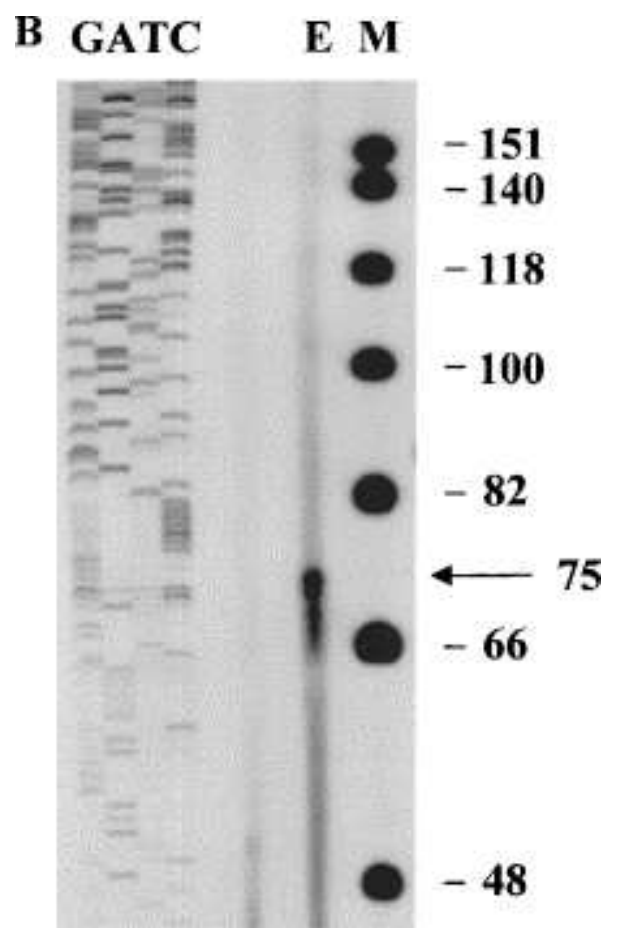

Fig. 2. (A) Nucleotide sequence of $2.5 \mathrm{~kb}$ of the Mistl 5 '-flanking region, exon I and intron I. The initiation ATG (in bold) is located in exon II. The arrow denotes the transcription start site at +1 . Potential transcription factor binding consensus sequences are indicated: E-boxes: E1 to E21, Sp1, PU.1 and AP2 sites, as well as a C/A repeat (boxed) and a T/A-rich region (underlined). (B) Determination of the transcription start site by $5^{\prime}$ extension analysis. Rat spleen poly $(\mathrm{A})^{+}$RNA was used as the starting material. A sequencing ladder and molecular weight markers (lane $\mathrm{M}, \mathrm{bp}$ ) were run on the left- and right-hand sides, respectively. The extension product (lane $\mathrm{E}$ ) is indicated by an arrow. 

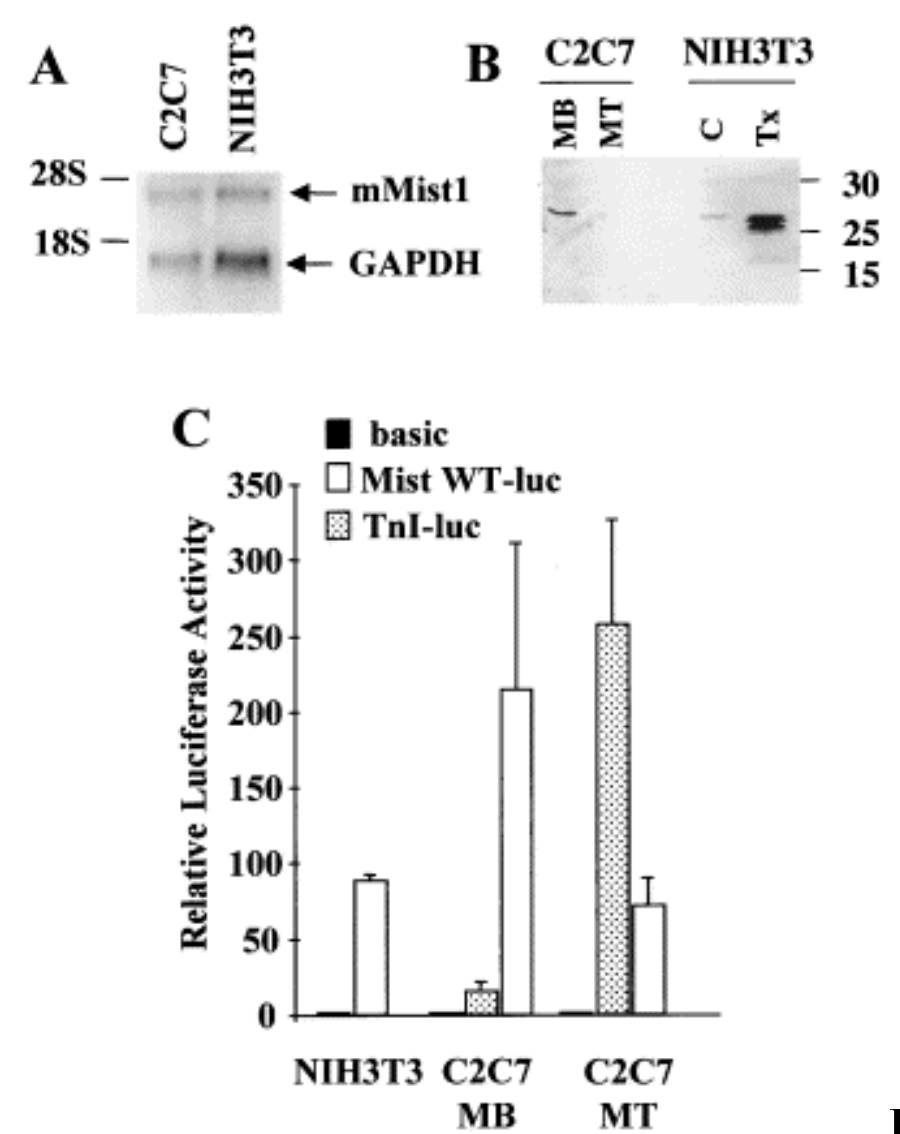

Fig. 3. The Mistl gene is active in

NIH3T3 and in C2C7 cells. (A) Fifteen micrograms of total RNA were fractionated through a denaturing agarose gel, transferred to nitrocellulose membrane, and subsequently hybridized with a mouse Mistl probe and a GAPDH cDNA. C2C7: myoblasts, NIH3T3: embryo fibroblasts. The position of the $28 \mathrm{~S}$ and $18 \mathrm{~S}$ ribosomal RNA is indicated. (B) Western blot analysis of Mist1 protein expression. Total cell extracts were prepared from $\mathrm{C} 2 \mathrm{C} 7$ cells [proliferating myoblasts (MB) or terminally differentiated myotubes (MT)] and from NIH3T3 cells [control $(\mathbf{C})$ or from cells tranfected with $10 \mu \mathrm{g}$ of pcDNA-Mist 1 expression vector (Tx)]. After separation on a 12\% SDS-PAGE gel, Mist expression was detected by Western blot using an anti-Mist1 polyclonal serum. Molecular weight markers are given in $\mathrm{kDa}$ on the right-hand side. The lower band in the transfected Mist1 lane is due to an internal translation initiation site. (C) A $2.5 \mathrm{~kb}$ fragment of Mistl 5' flanking sequence allows the expression of a reporter gene in NIH3T3 and in $\mathrm{C} 2 \mathrm{C} 7$ cells. NIH3T3 fibroblats and $\mathrm{C} 2 \mathrm{C} 7$ myoblasts (MB) were transfected with $2 \mu \mathrm{g}$ of Mist WT-Luc reporter (white bar), with $2 \mu \mathrm{g}$ of TnI-luc reporter (troponin I enhancer linked to the luciferase gene, gray bar) or with a promoter-less control plasmid (black bar). Cell extracts were prepared after $48 \mathrm{~h}$ and assayed for luciferase activity. In some experiments, $\mathrm{C} 2 \mathrm{C} 7$ were induced to differentiate into myotubes (MT) in low serum medium. Data are expressed as fold over the promoter-less control (pGL2 basic). 

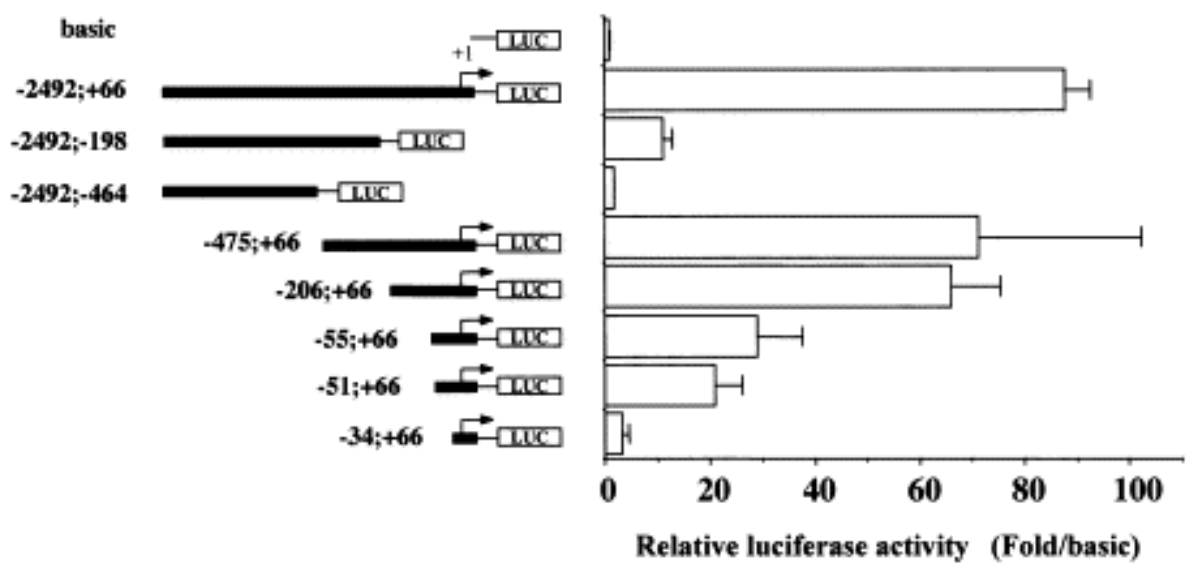

basic

WT

$\Delta 1$

$\Delta 2$

$\Delta 3$

$\Delta 4$

$\Delta 6$

$\Delta 5$

$\Delta 7$

Fig. 4. Deletion analysis of the Mist $15^{\prime}$ flanking region. NIH3T3 cells were transfected with $2 \mu \mathrm{g}$ of the various Mist 1 promoter fragments linked to a luciferase reporter gene. Forty-eight hours post-transfection, cell extracts were harvested and assayed for luciferase activity. The data are expressed as fold over the promoter-less control (pGL2 basic). 

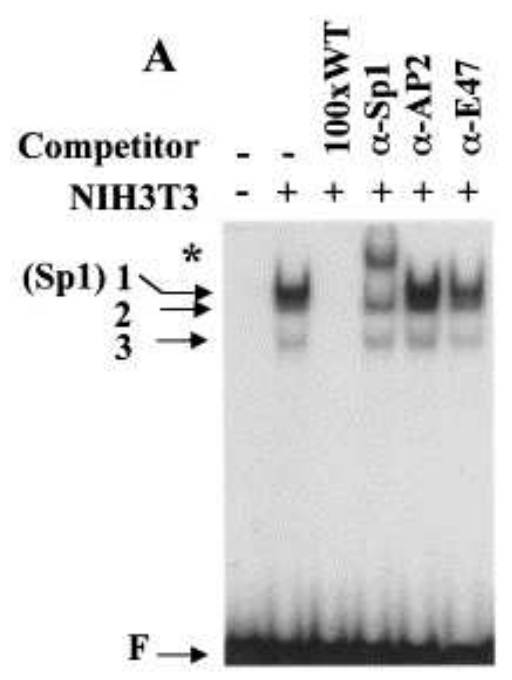

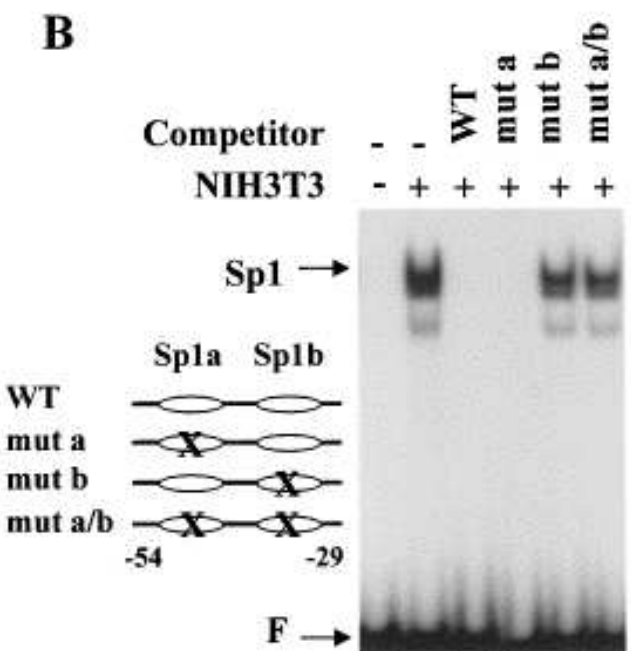

Fig. 5. Sp 1 binds to the $\mathrm{Sp} 1$ site $\mathrm{b}$ of the -54 to -29 Mist 1 DNA fragment. EMSA were performed using NIH3T3 nuclear extracts and $50 \mathrm{fmol}$ of a ${ }^{32} \mathrm{P}-$ labeled double-stranded oligonucleotide. (A) The DNA probe was incubated with NIH3T3 extract $(+)$ alone or with an 100 -fold molar excess of the unlabeled oligonucleotide $(100 \times$ WT $)$ or with $300 \mathrm{ng}$ of polyclonal antibodies raised against Sp1 ( $\alpha$-Sp1), AP2 ( $\alpha$-AP2) or E47 ( $\alpha$-E47). The positions of the three detected complexes are indicated. Sp1 corresponds to complex 1. '*' and F denote the supershifted Sp1 band and the free probe, respectively. (B) Mutations disrupting the Sp1 site a (mut a), site b (mut b), or both sites simultaneously (mut $a / b$ ), were introduced in the -54 to -29 oligonucleotide. The mutated probes were then tested in competition experiments. NIH3T3 extracts were incubated with ${ }^{32}$ P-labelled $-54 ;-29$ probe, in the presence of a 100fold excess of the cold wild type (WT) or the mutated competitors. The data indicate that Sp1 only binds to site b. (C) To confirm the importance of the Sp1 site b for Mist 1 promoter activity, this region was mutated by PCR to generate the $\Delta 4$ mut Sp 1 b construct linked to the luciferase gene. The activity of this latter construct was then tested by transient DNA transfection in NIH3T3 cells, along with the control counterpart $(\Delta 4)$. Results are expressed as fold over the promoter-less plasmid (basic). 

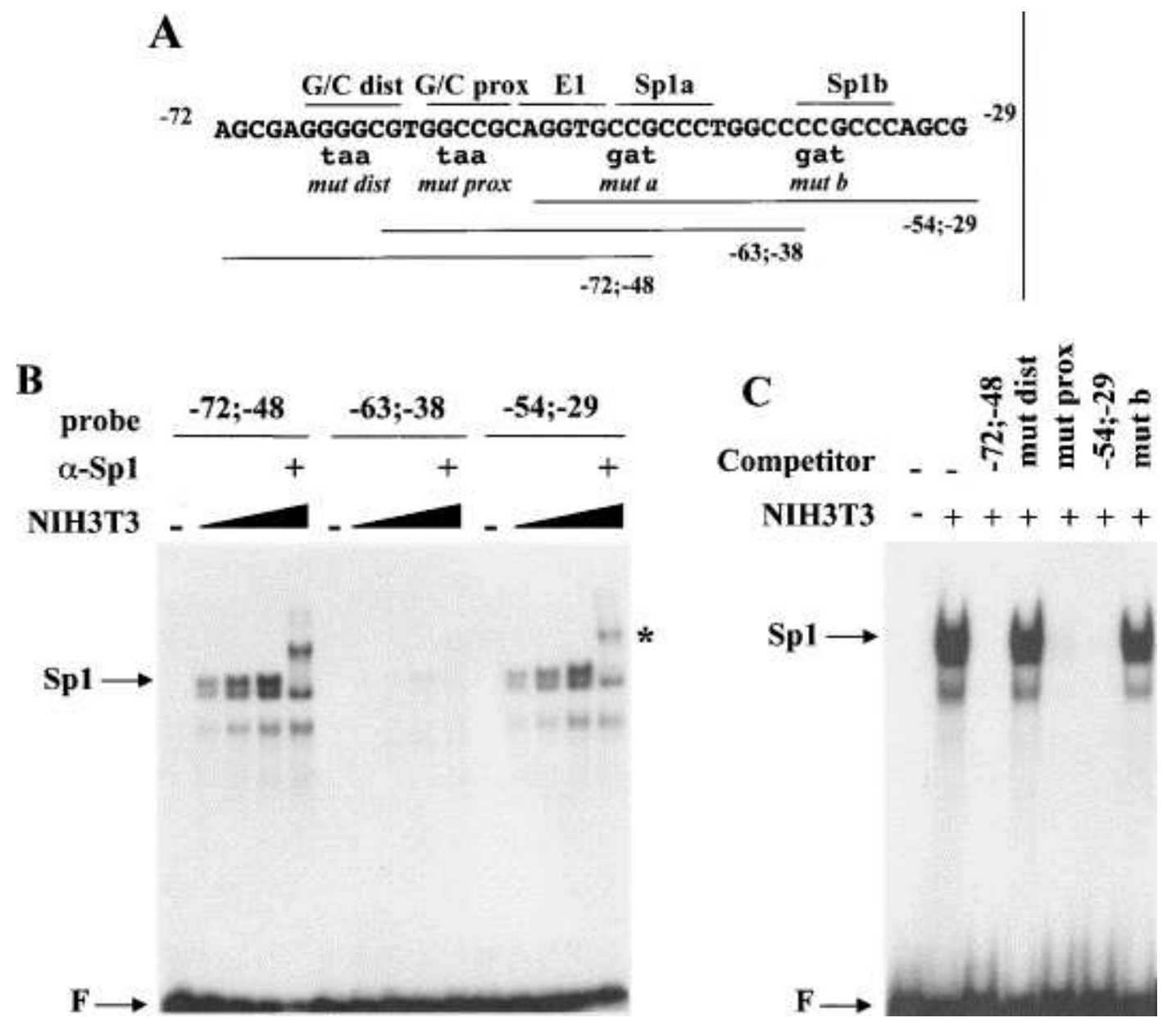

Fig. 6. (A) Sequence of the $-72 ;-29$ promoter region. The mutated nucleotide in mutant distal (mut dist), mutant proximal (mut prox), mutant a (mut a) and mutant $b$ (mut b) are indicated in lower case. (B) Sp1 binds to several sites in the proximal Mistl promoter. The presence of additional Sp1 sites was investigated by EMSA. Increasing amounts of NIH3T3 nuclear extract $(0-10 \mu \mathrm{g})$ were incubated with $50 \mathrm{fmol}$ of the following oligonucleotides: $(-54 ;-29),(-63 ;-38)$ and $(-72 ;-48)$. Where indicated $(+)$, the identity of the bound proteins was confirmed using the $\alpha-S p 1$ antibody. '*' and F denote the supershifted Sp1 complex and free probe, respectively. (C) The distal G/C element binds Sp1 in EMSA. ${ }^{32}$ P-labelled -72 ; -48 probe was incubated with NIH3T3 nuclear extracts, in the presence of a 100-fold molar excess of cold competitor. Mutations are present on the $\mathrm{G} / \mathrm{C}$ distal (mut dist) or proximal (mut prox) region [see (A)]. F: free probe. 